\title{
Pengembangan Media Video Animasi 3D Dalam Permainan Tradisional Petak Benteng Untuk Keterampilan Motorik
}

\author{
Dinar Ayu Mirunggan Sari*, Murtono, Irfai Fathurohman \\ Magister Pendidikan Dasar, Universitas Muria Kudus, Indonesia
}

\begin{abstract}
The purpose of this research is to explain the ddevelopment of $3 \mathrm{D}$ animated video media in traditional games of petak benteng for motor skills. The children (students) began to recognize the traditional game of petak benteng. Researchers developed a traditional game of petak benteng by using it as a 3D animated video to introduce the game. So that the game is not inferior to modern games. This researcher is a research and development $(\mathrm{RnD})$. Sources of fata in this study are primary data and secondary data. The data techniques, and interviews. The result of this research is that $3 \mathrm{D}$ aniamtion video learning media for students tradisional games, 3D animation video for the introduction of traditional games can be used to improve studentts motor skills, and 3D animation videos can be used as online learning media.
\end{abstract}

\section{ABSTRAK}

Tujuan dari penelitian yaitu menjelaskan pengembangan media video animasi 3D dalam permainan tradisional petak benteng untuk keterampilan motorik. Permainan tradisional petak benteng mulai jarang dikenal oleh anak-anak (siswa). Peneliti melakukan pengembangan pada permainan tradisional petak benteng dengan dijadikan video animasi 3D untuk mengenalkan permainan tersebut. Agar permainan tersebut tidak kalah dengan permainan modern. Peneliti ini adalah penelitian research and development (RnD). Sumber data di penelitian ini adalah data primer dan data sekunder. Teknik pengumpulan data yang digunakan adalah observasi, dokumentasi, angket, dan wawancara. Hasil penelitian adalah media pembelajaran video animasi 3D permainan tradisional petak benteng dapat digunakan dalam mengenalkan permainan tradisional kepada siswa, video animasi 3D pengenalan permainan tradisional petak benteng dapat digunakan untuk peningkatan keterampilan motorik siswa, dan video animasi 3D dapat dijadikan media pembelajaran online.

\section{CONTACT \\ saridinarayumirunggan@gmail.com \\ KEYWORDS \\ Video Animasi 3D, Permainan Tradisional, Keterampilan Motorik}

Received: 26/01/2021

Revised: 30/01/2021

Accepted: 20/03/2021

Online: $25 / 04 / 2021$

Published: 30/04/2021

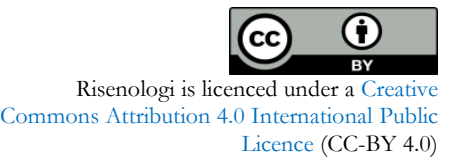

\section{INTRODUCTION}

Dunia anak merupakan dunia untuk bermain. Di dalam permainan anak akan memiliki jiwa bermain. Permainan anak dapat mempengaruhi perkembangan pribadinya. Ada beberapa permainan yang mampu untuk meningkatkan keterampilan motorik anak. Pendidikan anak usia dini berdasarkan Peraturan Menteri Pendidikan dan Kebudayaan Republik Indonesia No.137 Tahun 2014 tentang Standar Nasional Pendidikan Anak Usia Dini Pasal 1 Ayat 10 dinyatakan bahwa: "Pendidikan anak usia dini adalah upaya pembinaan yang ditujukan kepada anak sejak lahir sampai usia 6 (enam) tahun yang dilakukan melalui pemberian rangsangan pendidikan untuk membantu partumbuhan dan perkembangan jasmani dan rohani agar anak memiliki kesiapan dalam memasaki pendidikan lebih lanjut". (Masitha et al., 2021)

Permainan tradisional merupakan simbolisasi dari pengetahuan yang turun nenurun dan mempunyai bermacam- macam fungsi atau pesan dibaliknya Hayuningtyas, permainan tradisional merupakan hasil budaya yang besar nilainya bagi anak- anak dalam rangka berfantasi, berekreasi, berkreasi, berolah raga yang sekaligus sebagai sarana berlatih untuk kehidupan bermasyarakat, ketrampilan, kesopanan, serta ketegasan (Ahmad, 2016).

Peneliti menemukan beberapa permasalahan yakni permainan tradisional yang mulai dilupakan oleh anakanak, keterampilan anak yang perlu ditingkatkan dan media pembelajaran yang menunjang di dalam peningkatan keterampilan motorik anak. Peneliti memberikan solusi yakni dengan melakukan pengembangan media video animasi 3D dalam permainan tradisional petak benteng untuk keterampilan motorik. Animasi 3D memiliki kelebihan dalam memvisualisasikan konsep pelajaran dengan sangat baik (Bakri \& Muliyati, 2021; Bakri, 2019a), dalam banyak penelitian, 3D juga dapat divisualisasikan dalam bentuk augmented reality (e.g., Bakri et al., 2019b; Bakri, 2019c; Bakri \& Wahyuni., 2021; Sumardani, Wulandari et al, 2019; Sumardani, Saraswati, et al., 2020; Sumardani, Ramadhan, et al., 2020) atau virtual reality (e.g., Sumardani \& Midaraeni, 2019; Sumardani \& Putri, 2020). Dalam penelitian ini kamu berfokus pada visualisasi menggunakan video. 
Permainan tradisional mampu digunakan untuk melatih kemampuan untuk membaca dalam gerak tubuh, mengerakkan anggota tubuh, mampu melatih dalam hal tangkas dan lincah di dalam permainan, mampu dalam peningkatkan keterampilan komunikasi dan keterampilan dalam menyusun hal-hal strategi yang baik, mampu melepaskan emosi dan dapat melatih keterampilan anak dalam belajar kelompok. Anak akan menjadi aktif di dalam pembelajaran untuk pengembangan fisik motorik dan memiliki minat dan motivasi dalam permainan sehingga hati akan merasa senang. (Masitha et al., 2021).

Permainan tradisonal merupakan simbolisasi dari pengetahuan yang turun temurun dan mempunyai bermacam-macam fungsi atau pesan di baliknya, di mana pada prinsipnya permainan anak tetap merupakan permainan anak (Hanief \& Sugito, 2015). Permainan kerakyatan merupakan suatu bentuk menginformasikan keberagaman budaya, terutama terkait suku yang ada ditempat tersebut. Keberadaan permainan tersebut penting diketahui dan dikenali oleh masyarakat secara umum dan khususnya di kalangan mahasiswa. (Vinet \& Zhedanov, 2011)

Permainan tradisional "Benteng" adalah permainan asli dengan budaya dari Bangsa Indonesia dengan nama yang berbeda-beda di setiap daerah. Peraturan permainan tradisional bentengan diterbitkan oleh Direktorat Keolahragaan Direktorat Jenderal Pendidikan Luar Sekolah, Pemuda dan Olahraga Departemen Pendidikan dan Kebudayaan Republik Indonesia pada tahun 1985, sejarah dari perkembangan dalam permainan tradisional "Bentengan" ini tidak dapat diketahui pasti, sejak papda masa anak dan generasi kakek dan nenek. Permainan sudah mulai dikenal, digemari dan dapat dimainka. Permainan ini dilakukan dengan berkelompok. Dengan berusaha saling melakukan serangan dan mempertahankan benteng. Menghindari diri dari lawan untuk menangkap atau disentuh. (Hanief \& Sugito, 2015)

Permainan tradisional bebentengan menurut Sujarno, dkk (2013, hlm. 26) adalah salah satu jenis permainan (anak- anak) tradisional masyarakat. Bentengan berasal dari kata "benteng" dengan imbuhan "an". Betengan berasal dari Bahasa Iawa yang di Indonesiakan "Benteng". Berdasarkan pemikiran. (Saputra, 2019). Perkembangan motorik adalah sesuatu proses kemasakan atau gerak yang langsung melibatkan otot-otot untuk bergerak dan proses persyarafan yang menjadi seseorang mampu menggerakkan tubuhnya (Sukamti, 2014) dalam (Ahmad Nur Rohim, Fella Sufah Baedowi, Fitria Indah Susanti, Ismi Aflahal Mari’ah, 2020).

Keterampilan motorik dibedakan menjadi dua yakni keterampilan motorik kasar dan halus. Pada keterampilan motorik kasar adalah keterampilan dalam gerak yyang menggunakan otot besar. Tujuannya adalah kecermatan dalam gerakan. Keterampilan motorik halus (fine motor skill) secara umum meliputi koordinasi mata dan tangan serta membutuhkan kecermatan yang tinggi (Ahmad Nur Rohim, Fella Sufah Baedowi, Fitria Indah Susanti, Ismi Aflahal Mari'ah, 2020).

Tujuan pengembangan motorik pada anak usia dini yaitu membantu meningkatkan keterampilan fisik motorik anak dalam melatih gerakan motorik kasar dan halus, meningkatkan kemampuan mengelola dan mengontrol gerakan tubuh, serta meningkatkan keterampilan tubuh dan cara hidup sehat sehingga dapat menunjang pertumbuhan jasmani yang kuat, sehat dan terampil (Sujiono, 2010). (Afifah Hanum, 2020)

Peneliti melakukan pengembangan media video animasi 3D dalam permainan tradisional petak benteng untuk keterampilan motorik. Pengembangan ini berupa langkah-langkah permainan tradisional petak benteng dan diubah menjadi video animasi 3D yang dapat membantu meningkatkan keterampilan motorik. Media video animasi 3D ini peneliti buat menggunakan aplikasi adobe profesional.

\section{METHODS}

Tujuan penelitian yaitu menjelaskan pengembangan media video animasi 3D dalam permainan tradisional petak benteng untuk keterampilan motorik. Penelitian yang digunakan yakni penelitian Research and Development $(\mathrm{RnD})$. Sumber data yakni data primer dan sekunder. Teknik dari pengumpulan data pada penelitian ini adalah observasis, dokumentasi, angket, dan wawancara. Penelitian ini menggunakan dua kelas yakni kelas eksperimen (39 siswa) dan kelas kontrol (37 siswa). Dalam penelitian Research and Development ini diuji normality test, homogeneity test, dan indepent sample test.

\section{RESULTS AND DISCUSSIONS}

Pengembangan media video animasi 3D dalam permainan tradisional petak benteng untuk keterampilan motorik ini menghasilkan produk yakni media pembelajaran interaktif berupa video animasi 3D yang berisi mengenai cara bermain permainan tradisional petak benteng. Cara menggunakan media video animasi 3D ini yaitu dikaitkan dengan mata pelajaran yang diajarkan.

Cara bermain permainan tradisional petak benteng di dalam video animasi seperti di dalam buku yang penulis buat yakni 
1. Kelompok menentukan bentengnya.

2. Masing-masing kelompok menawan anggota kelompok lawan.

3. Permainan dimulai dengan satu anggota kelompok keluar dari benteng.

4. Demikian seterusnya, secara bergantian.

5. Cara menghindari untuk disentuh, pemain dapat kembali ke bentengnya.

6. Anggota yang tersentuh akan ditawan di benteng lawan.

7. Teman satu kelompok dapat menyelamatkan dengan cara mendatangi benteng lawan dan menyentuh mereka tetapi tidak boleh tersentuh lawan.

8. Saat anggota kelompoj menyelamatkan teman-temannya yang tertawan, anggota kelompok yang tingggal agar menjaga benteng.

9. Jika benteng tersentuh oleh lawan, maka kelompok lawan yang menang. (Sari, 2021:57-59)

Manfaat dari permainan petak benteng yakni 1) melatih minat dan kerjasama, 2) menaati peraturan, 3) dapat berinteraksi satu sama lain, 4) menyusun rencana bersama kelompok, 5) melatih berorganisasi dan berbagi peran di dalam permainan, 6) menjaga anggota kelompok, 7) melatih motorik kasar. (Sari, 2021:58)

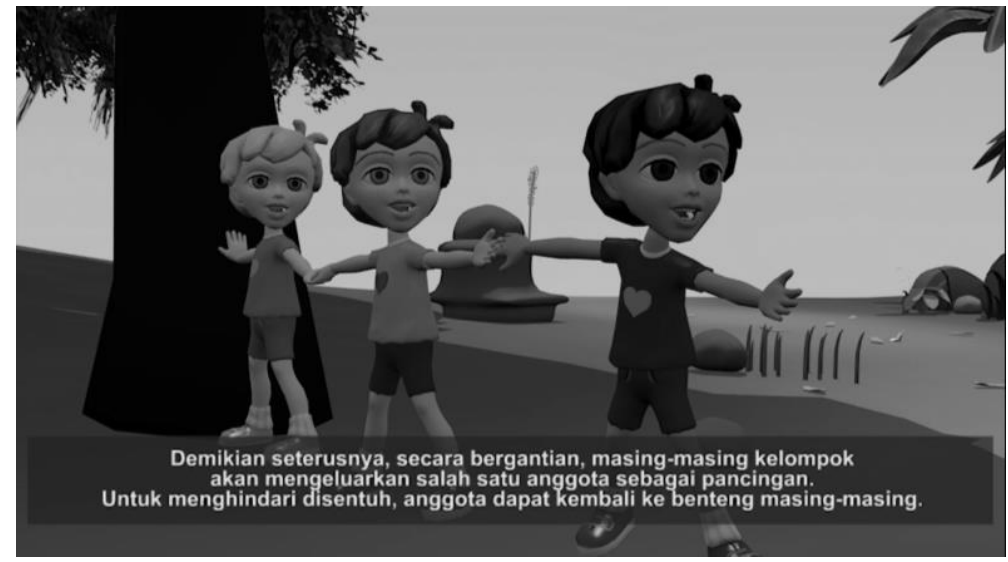

Gambar 1 Animasi Permainan Petak Benteng

Video animasi 3D ini bertujuan untuk mengenalkan permainan tradisional dan peningkatan keterampilan motorik. Pengembangan media video animasi 3D dalam permainan tradisional petak benteng untuk keterampilan motorik diuji yakni 1) uji normalitas, 2) uji homogenitas, 3) uji independent sampel, dan 4) uji $\mathrm{N}$-gain sebagai berikut.

Tabel 1 Kelas Eksperimen dan Kontrol

\begin{tabular}{|l|l|}
\hline \multicolumn{1}{|c|}{ Kelas } & Jumlah \\
\hline Eksperimen & 39 siswa \\
\hline Kontrol & 37 siswa \\
\hline
\end{tabular}

Tabel 2 Tests of normality

Tests of Normality

\begin{tabular}{|l|l|r|r|r|r|r|r|}
\hline & Kelas Eksperimen & \multicolumn{3}{|c|}{ Kolmogorov-Smirnov } & \multicolumn{3}{|c|}{ Shapiro-Wilk } \\
\cline { 3 - 8 } & dan Kelas Kontrol & Statistic & df & \multicolumn{1}{c|}{ Sig. } & \multicolumn{1}{c|}{ Statistic } & df & \multicolumn{1}{c|}{ Sig. } \\
\hline Keterampilan & Eksperimen & .116 & 39 & $.200^{*}$ & .962 & 39 & .202 \\
Motorik & Kontrol & .122 & 37 & .184 & .959 & 37 & .186 \\
\hline
\end{tabular}

*. This is a lower bound of the true significance.

a. Lilliefors Significance Correction

Simpulan dari tabel 1 tests of normality yakni dapat dilihat data signifikansi kolmogorov-smirnow pada eksperimen sig. $=.200$ (berdistribusi normal) dan kontrol sig. $=.184$ (berdistribusi normal). Menurut shapiro-wilk eksperimen sig. $=.202$ (berdistribusi normal) dan kontrol sig. $=.186$ (berdistribusi normal).

Tabel 3 Test of homogeneity of variances

Test of Homogeneity of Variances

Keterampilan Motorik

\begin{tabular}{|c|c|c|c|}
\hline Levene Statistic & df1 & $\mathrm{df} 2$ & Sig. \\
\hline .000 & 1 & 74 & .985 \\
\hline
\end{tabular}


Berdasarkan tabel 2 test of homogeneity of variances dapat simpulkan bahwa sig. $=.985$ yang berarti homogen.

Tabel 4 Independent samples test

Independent Samples Test

\begin{tabular}{|c|c|c|c|c|c|c|c|c|c|c|}
\hline & \multicolumn{2}{|c|}{$\begin{array}{l}\text { Levene's } \\
\text { Test for } \\
\text { Equality of } \\
\text { Variances } \\
\end{array}$} & \multicolumn{7}{|c|}{ t-test for Equality of Means } \\
\hline & & \multirow[b]{2}{*}{$\mathbf{F}$} & \multirow[b]{2}{*}{ Sig. } & \multirow[b]{2}{*}{$t$} & \multirow[b]{2}{*}{ df } & \multirow{2}{*}{$\begin{array}{l}\text { Sig. (2- } \\
\text { tailed) }\end{array}$} & \multirow{2}{*}{$\begin{array}{c}\text { Mean } \\
\text { Difference }\end{array}$} & \multirow{2}{*}{$\begin{array}{l}\text { Std. Error } \\
\text { Difference }\end{array}$} & \multicolumn{2}{|c|}{$\begin{array}{l}\text { 95\% Confidence } \\
\text { Interval of the } \\
\text { Difference }\end{array}$} \\
\hline & & & & & & & & & Lower & Upper \\
\hline $\begin{array}{l}\text { Keterampilan } \\
\text { Motorik }\end{array}$ & $\begin{array}{l}\text { Equal variances } \\
\text { assumed }\end{array}$ & .000 & .985 & 3.126 & 74 & .003 & 1.590 & .509 & .576 & 2.603 \\
\hline & $\begin{array}{l}\text { Equal variances } \\
\text { not assumed }\end{array}$ & & & 3.119 & 72.644 & .003 & 1.590 & .510 & .574 & 2.606 \\
\hline
\end{tabular}

Hasil tabel 3 independet samples test dapat dilihat nilai sig. (2-tailed) yakni 0.003 yang memiliki arti yakni lebih kecil dari 0.05. Maka disimpulkan bahawa independent samples test yakni terdapat perbedaan yang signifikan pada pengembangan media video animasi 3D dalam permainan tradisional petak benteng untuk keterampilan motorik.

Berdasarkan hasil perhitungan uji N-Gain score menunjukkan bahwa nilai rata-rata N-Gain score pada kelas eksperimen adalah 58.3008 atau 58\% termasuk kategori cukup efektif dengan nilai N-Gain score minimal 33\% dan N-Gain score maksimal 80\%. Sedangkan rata-rata N-Gain score pada kelas kontrol adalah 34.3882 atau $34 \%$ termasuk kategori tidak efektif dengan nilai N-Gain score minimal $-66.67 \%$ dan maksimal 72.22\%. Maka dapat disimpulkan bahwa penggunaan pengembangan media video animasi $3 \mathrm{D}$ dalam permainan tradisional petak benteng untuk keterampilan motorik.

Penelitian ini diperkuat dengan penelitian sebelumnya yakni komponen-komponen dalam keterampilan motorik kasaar dengan kegiatan-kegiatan lompat tali. Sebelum melakukan tindakan didapatkan 14,28\% (2 siswa dari 14 siswa = baik), siklus I didapatkan 71\% (10 siswa dari 14 siswa = baik). Pada siklus II didapatkan 93\% (13 siswa dari 14 siswa = baik). Anak dengan gerakan lompat dengan menolak kuat sehingga dapat mendarat dengan kriteria baik. (Masitha et al., 2021).

\section{CONCLUSIONS}

Hasil penelitian yang peneliti lakukan yakni media pembelajaran video animasi 3D permainan tradisional petak benteng dapat digunakan dalam mengenalkan permainan tradisional kepada siswa, video animasi 3D pengenalan permainan tradisional petak benteng dapat digunakan untuk peningkatan keterampilan motorik siswa, dan video animasi 3D dapat dijadikan media pembelajaran online. Media pembelajaran video animasi 3D dari permainan tradisional petak benteng ini merupakan video yang dapat membantu dalam peningkatan keterampilan motorik. Di dalam video animasi tidak hanya langkah-langkah dari cara bermain. Namun ada beberapa sub yakni arti dari permainan petak benteng, video langkah-langkah, manfaat dari permainan, dan manfaat yang di dapatkan dari permainan tradisional tersebut.

\section{REFERENCES}

Afifah Hanum, R. (2020). Kegiatan sentra olah tubuh dalam menstimulasi kemampuan motorik kasar anak. Jurnal AUDHI, 2(2).

Rohim, A. N., Baedowi, F. S., Susanti, F. I., Mari’ah, I. A., \& Bumi, D. C. B. B. (2021). Merajut keterampilan motorik melalui edukasi dan pelatihan hidroponik berbasis pendidikan vokasional di Pondok Pesantren Modern Madania Yogyakarta. Prosiding Seminar Nasional Fakultas Pertanian UPN “Veteran” Yogyakarta 2020, 306-314.

Ahmad, T. (2016). Tradisional Jawa Ahmad Tabi ' in. MAGISTRA, 7(1), 1-26.

Bakri, F., Sumardani, D., \& Muliyati, D. (2019a). The 3D simulation of Lorentz Force based on augmented reality technology. Journal of Physics: Conference Series 1402(6), 066038.

Bakri, F., Sumardani, D., \& Muliyati, D. (2019b). Integrating augmented reality into worksheets: Unveil learning to support higher-order thinking skills. AIP Conference Proceedings 2169, 020012. 
Bakri, F., Sumardani, D., \& Muliyati, D. (2019c). The augmented reality application for simulating electromotive force concept. Journal of Physics: Conference Series, 1402(6), 066039.

Bakri, F., Sumardani, D., \& Muliyati, D. (2021). Radioactive decay model based on augmented reality. Journal of Physics: Conference Series, 1869 (1), 012192.

Bakri, F., Wahyuni, Permana, A. H., \& Sumardani, D. (2021). Textbook enriched with video augmented reality: Contextual in motion concept learning in junior high school. AIP Conference Proceedings, 2320(1), 020054.

Hanief, Y. N., \& Sugito, S. (2015). Membentuk Gerak Dasar Pada Siswa Sekolah Dasar Melalui Permainan Tradisional. Jurnal SPORTIF: Jurnal Penelitian Pembelajaran, 1(1), 60-73.

Masitha, R., Noviardila, I., \& Pahrul, Y. (2021). Research \& Learning in Faculty of Education Peningkatan Kemampuan Motorik Kasar anak melalui Permainan Tradisional Lompat Tali di TK Kasih Ibu Padang Tarap Kampar Utara. Journal On Teacher Education 2, 35-41.

Saputra, R. (2019). Kualitas kepemilikan pengetahuan simbol melayu bidang permainan di kalangan mahasiswa. Journal of Chemical Information and Modeling, 53(9), 1689-1699.

Sari Dinar Ayu Mirunggan. 2021. Pengenalan Permainan Tradisional. Semarang : CV. Lentera Kata.

Sumardani, D., Wulandari, A., Ramdina S, A. N., \& Doriza, S. (2019). Penerapan teknologi augmented reality pada media pembelajaran poster tatasurya. Prosiding Seminar Nasional Fisika (E-Journal), 8, 451-456.

Sumardani D., Midaraeni I., Sumardani N.I., (2019). Virtual reality sebagai media pembelajaran relativitas khusus berbasis google cardboard pada smartphone android. Prosiding Seminar Nasional Pendidikan KALUNI, 2, 309-321.

Sumardani, D., Putri, A., Saraswati, R., Muliyati, D., \& Bakri, F. (2020). Virtual Reality Media: The Simulation of Relativity Theory on Smartphone. Formatif: Jurnal Ilmiah Pendidikan MIP A, 10(1), 13-24.

Sumardani, D., Saraswati, R., Putri, A., Bakri, F., \& Muliyati, D. (2020). System implementation of augmented reality application in student worksheet. Informatika, 8(1), 10-18.

Sumardani, D., Putri, A., Ramadhan, Z., Bakri, F., \& Muliyati, D. (2020). Augmented Physics' Lab: Magnetic Field Use Virtual Learning Media for 21st Century Students. Jurnal Pembelajaran Fisika, 8(1), 61-70.

Vinet, L., \& Zhedanov, A. (2011). A “missing” family of classical orthogonal polynomials. Journal of Physics A: Mathematical and Theoretical, 44(8), 1689-1699. 